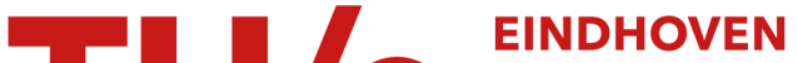 UNIVERSITY OF TECHNOLOGY
}

\section{An experimental and numerical investigation into the single- fibre fragmentation test : stress transfer by a locally yielding matrix}

\section{Citation for published version (APA):}

van den Heuvel, P. W. J., Hogeweg, B., \& Peijs, A. A. J. M. (1997). An experimental and numerical investigation into the single-fibre fragmentation test: stress transfer by a locally yielding matrix. Composites. Part A: Applied Science and Manufacturing, 28(3), 237-249. https://doi.org/10.1016/S1359-835X(96)00114-5

DOI:

10.1016/S1359-835X(96)00114-5

Document status and date:

Published: 01/01/1997

\section{Document Version:}

Publisher's PDF, also known as Version of Record (includes final page, issue and volume numbers)

\section{Please check the document version of this publication:}

- A submitted manuscript is the version of the article upon submission and before peer-review. There can be important differences between the submitted version and the official published version of record. People interested in the research are advised to contact the author for the final version of the publication, or visit the DOI to the publisher's website.

- The final author version and the galley proof are versions of the publication after peer review.

- The final published version features the final layout of the paper including the volume, issue and page numbers.

Link to publication

\footnotetext{
General rights

- You may freely distribute the URL identifying the publication in the public portal. follow below link for the End User Agreement:

www.tue.nl/taverne

\section{Take down policy}

If you believe that this document breaches copyright please contact us at:

openaccess@tue.nl

providing details and we will investigate your claim.
}

Copyright and moral rights for the publications made accessible in the public portal are retained by the authors and/or other copyright owners and it is a condition of accessing publications that users recognise and abide by the legal requirements associated with these rights.

- Users may download and print one copy of any publication from the public portal for the purpose of private study or research.

- You may not further distribute the material or use it for any profit-making activity or commercial gain

If the publication is distributed under the terms of Article $25 \mathrm{fa}$ of the Dutch Copyright Act, indicated by the "Taverne" license above, please 


\title{
An experimental and numerical investigation into the single-fibre fragmentation test: stress transfer by a locally yielding matrix
}

\author{
P. W. J. van den Heuvel, B. Hogeweg and T. Peijs* \\ Eindhoven University of Technology, Centre for Polymers and Composites, PO Box 513, \\ $5600 \mathrm{MB}$ Eindhoven, The Netherlands \\ (Received 13 March 1996; revised 26 June 1996)
}

\begin{abstract}
Single-fibre fragmentation tests on carbon/epoxy microcomposites were performed using carbon fibres with surface treatment levels varying from 0 to $200 \%$ of the commercial fibre surface treatment, i.e. $100 \%$. Polarized light microscopy showed substantial local matrix yielding near the fibre-matrix interface in the case of good fibre-matrix adhesion. The level of fibre surface treatment proved to have a large influence on both the final fragment length distribution and the debonded length. The experimental fragment length distributions were compared to predicted fragment length distributions resulting from a numerical simulation of the fibre fragmentation test, based on stress transfer through a yielding matrix and frictional shear stress. Good agreement between the experimental results and the predictions was observed for the case of little debonding. Because of the observed stress transfer through a locally yielding matrix, the classical stress transfer theories for the fibre fragmentation test do not determine a realistic value for the strength of the fibre-matrix interface. (C) 1997 Elsevier Science Limited. All rights reserved.
\end{abstract}

(Keywords: fibre fragmentation test; numerical simulation; carbon fibre/epoxy composites; surface treatment)

\section{INTRODUCTION}

Over the years it has been well established that the strength and toughness of fibre-reinforced materials is determined to a great extent by the interface between the reinforcing fibres and the matrix. Therefore, the determination of the interface strength has been given much attention. Several experimental techniques have been developed to measure the strength of the fibre-matrix interface: the fibre fragmentation test, the pull-out test, the microbond test and the microindentation test ${ }^{1}$. In order to obtain a value for the fibre-matrix interface strength from the experimental data, theoretical models describing the stress transfer from the matrix to the fibre are required. Many theoretical models have been proposed, all differing in the way the stress is transferred from the matrix to the fibre ${ }^{2-5}$. For instance, the well known shear-lag theory proposed by Cox considers perfect fibre-matrix adhesion and both the fibre and the matrix are assumed to be elastic ${ }^{2}$. Kelly and Tyson also considered perfect adhesion and an elastic fibre, but, in contrast to Cox, assumed that a constant shear stress builds up the stress in a fibre ${ }^{3}$. An adaptation of Cox's model was presented by Lhotellier and Brinson ${ }^{4}$. Based

* To whom correspondence should be addressed on Cox's shear-lag theory they considered an interphase zone, i.e. a transition zone in-between the bulk matrix and the fibre surface, in which the possibility of matrix yielding at a constant deformation rate was introduced. A stress transfer model including fibre-matrix debonding was proposed by Piggott ${ }^{5}$. In this model, a constant frictional shear stress was assumed to build up the stress in the fibre in the debonded areas, whereas in the wellbonded regions stress transfer takes place according to Cox's model with a maximum possible shear stress equal to the matrix yield stress.

Despite the progress made in the experimental techniques, such as Raman spectroscopy ${ }^{6,7}$, as well as in the stress transfer theories, a recent round robin evaluation showed that a proper determination of the interface strength is still not possible ${ }^{8}$. This is mainly due to a poor understanding of the relationship between the stress transfer models and the actual experiments. A powerful method to investigate the relationship between experiment and theory is to compare experimental results with predictions of a numerical simulation of the experiment. In this paper such a comparison is made for the fibre fragmentation test. In a fibre fragmentation test, a single filament, centrally embedded in a dumb-bell shaped tensile bar, is subjected to a tensile load. When the stress transferred to the fibre through the interface 
reaches the failure stress of the fibre, the fibre fails. As the level of applied stress increases, the fragmentation process continues until the fibre fragments have become so short that the transferred stress is insufficient to reach the breaking stress of the fibre, i.e. the fragmentation process is saturated. Provided that the matrix is transparent, microscopic failure phenomena such as fibre fracture, fibre-matrix debonding, local matrix yielding and matrix cracking can be easily observed through an optical microscope.

In general, numerical simulations of the fibre fragmentation test are based on randomly placing flaws along a fibre according to a Poisson distribution, either before $^{9}$ or during the simulation ${ }^{10-12}$. Each flaw is assigned a certain strength according to, for instance, a Gaussian distribution ${ }^{10}$ or a Weibull distribution ${ }^{1,12}$. Subsequently, a step in the stress is applied and breaks are uncovered along the fibre. Finally, the stress profile is calculated according to a stress transfer model, after which a new step in the stress is applied. This process ends when the fibre cannot accommodate another break, i.e. when the saturation level is reached. Ling and Wagner, for instance, performed such a numerical simulation of the single-fibre fragmentation test ${ }^{10}$. Four different fibre loading models were employed, one being the Kelly-Tyson model. However, a matrix yield stress of $80 \mathrm{MPa}$ was selected, which is a reasonable value for the yield stress in uniaxial tension but which is rather high considering the shear conditions present at the fibre-matrix interface. In addition, no comparison was made between the model predictions and experimental data. Favre et al. have made such a comparison for carbon/epoxy microcomposites ${ }^{9}$. Using a shear-lag stress transfer model including debonding, they found a relatively good agreement between the experimentally determined and predicted interfacial shear stress. However, Favre et al. correctly stated that the good agreement observed may be attributed to a properly selected coefficient of friction. Furthermore, in the shearlag analysis the results can be manipulated to a large extent by the matrix equivalent radius $R^{13}$. In addition, the possibility of matrix yielding near the fibre-matrix interface was not considered in Favre's evaluation of the fibre fragmentation process ${ }^{9}$. Another comparison between experimental fibre fragmentation results and numerical simulation predictions was presented by Netravali et al. $^{12}$. They performed a Monte-Carlo simulation of the fibre fragmentation test based on a PoissonWeibull model for fibre strength and flaw occurrence and a linear stress build-up in the fibre. Interfacial shear stresses of $\sim 48 \mathrm{MPa}$ were calculated and claimed to be originating from friction, but it was suspected that other factors play a role in the stress build-up as well ${ }^{12}$. It is our belief that one of these factors might be local yielding of the matrix near the fibre-matrix interface. Therefore, in this paper we present a comparison of experimental fibre fragmentation data with numerical simulation predictions including the occurrence of local matrix yielding and interfacial debonding.
In order to investigate the influence of fibre-matrix debonding on the fragmentation process, carbon fibres with surface treatment levels ranging from 0 (untreated) to $200 \%$ with respect to the commercial surface treatment level $(100 \%)$ were used. The experimental findings were compared with predictions resulting from a numerical simulation of the fibre fragmentation test developed by Curtin $^{14}$. He derived an exact solution of the relationship between the fibre fragmentation process and the underlying statistical fibre strength. In the first part of this paper, Curtin's simulation procedure will be briefly discussed and the influence of several parameters on the fibre fragmentation process will be shown. After presenting the experimental results, these results will be compared to the predictions of the numerical simulation.

\section{SIMULATION THEORY}

Curtin derived an exact solution for the relationship between the fibre fragmentation process and the underlying statistical fibre strength ${ }^{14}$. In his description of the fibre fragmentation process Curtin makes use of the stress recovery zone, in which the stress recovers from zero at the fibre break to the undisturbed stress $\sigma$ over a length $\delta(\sigma)$ (see Figure 1). It is assumed that within this stress recovery zone the fibre cannot possibly break at any applied stress, i.e. the stress recovery zone acts as an exclusion zone. This exclusion zone principle allowed Curtin to divide the fragments into two parts: (i) fragments longer than $\delta(\sigma)$ at the current stress level $\sigma$, and (ii) fragments smaller than $\delta(\sigma)$. The fragments smaller than $\delta(\sigma)$ will remain unchanged during the remainder of the test and are removed, i.e. stored into a distribution function $P_{\mathrm{R}}(x)$. The length distribution of the fragments longer than $\delta(\sigma)$ as a function of $\delta(\sigma)$ and the break density $n$ is known exactly and is denoted $P(x ; n, \delta)^{14,15}$. Curtin showed that this distribution function $P(x ; n, \delta)$ also determines the distribution

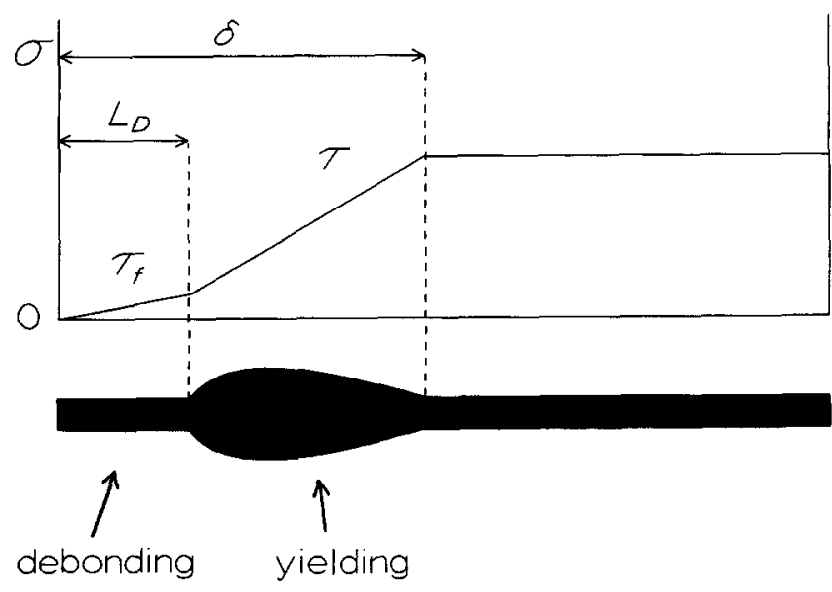

Figure 1 Schematic representation of stress $\sigma$ profile along a fibre embedded in a matrix. Stress transfer over a length $\delta$, the stress recovery or exclusion zone, via frictional shear stress caused by debonding over a length $L_{\mathrm{D}}$ followed by constant shear yield stress 
function $P_{\mathrm{R}}(x)$. The following relationships were derived by Curtin to describe the evolution of the number of breaks $N$, the remaining length $L$, the length of the remaining fibre able to incorporate another break $L^{*}$ and the removed distribution function $P_{\mathrm{R}}(x)$ as a function of the applied stress $\sigma$ :

$$
\begin{gathered}
\frac{\mathrm{d} N}{\mathrm{~d} \sigma}=-N P(\delta ; n, \delta)+f\left(\sigma, L^{*}\right) \\
\frac{\mathrm{d} L}{\mathrm{~d} \sigma}=-N \delta P(\delta ; n, \delta) \frac{\mathrm{d} \delta}{\mathrm{d} \sigma} \\
L^{*}=N \int_{2 \delta}^{\infty}(x-2 \delta) P(x ; n, \delta) \mathrm{d} x \\
\frac{\mathrm{d} P_{\mathrm{R}}}{\mathrm{d} \sigma}=N P(\delta ; n, \delta) \frac{\mathrm{d} \delta}{\mathrm{d} \sigma} \delta_{\mathrm{D}}(x-\delta)
\end{gathered}
$$

where $f\left(\sigma, L^{*}\right)$ represents a fibre strength distribution term and $\delta_{\mathrm{D}}()$ denotes the Dirac delta function ${ }^{14}$. Curtin assumed a unimodal Weibull distribution for the strength distribution term $f\left(\sigma, L^{*}\right)$ :

$$
f\left(\sigma, L^{*}\right)=\frac{L^{*}}{L_{0}} \frac{\rho}{\sigma_{0}}\left(\frac{\sigma}{\sigma_{0}}\right)^{\rho-1}
$$

where $L_{0}$ is the fibre length associated with the scalc parameter $\sigma_{0}$ and $\rho$ is the Weibull modulus. In order to make a more straightforward link with the experiments possible, we accommodated $L_{0}$ into $\sigma_{0}$ :

$$
f\left(\sigma, L^{*}\right)=L^{*} \frac{\rho}{\sigma_{0}^{*}}\left(\frac{\sigma}{\sigma_{0}^{*}}\right)^{\rho-1}
$$

where $\sigma_{0}^{*}=\sigma_{0} L_{0}^{1 / \rho}$.

Using equations (1)-(5), Curtin simulated the fibre fragmentation process for two different stress transfer models: 1) a linear stress transfer model according to Kelly and Tyson, in which the shear stress is a constant; and 2) a bilinear stress transfer model, in which the linear stress transfer model was improved by including a debonded area in which frictional stresses cause the stress build-up in the fibre. Following Henstenburg and Phoenix ${ }^{11}$, Curtin assumed that when a certain stress level was reached in the fibre, i.e. the debond stress, a debonded area starts to grow continuously upon further stress increase, at the expense of plastic stress transfer by the matrix. Thus, yielding is assumed to precede debonding ${ }^{11,14,16}$. Although this representation of the stress build-up in a fibre might be true for an unbroken fibre embedded in a matrix, it is incorrect for a rupturing fibre, as in the fibre fragmentation test. As often observed, a fibre break is immediately accompanied by the formation of a debonded region around the fibre break, caused by the sudden release of strain energy stored in the fibre ${ }^{17,18}$. Therefore, we modified the bilinear stress transfer model in such a way that each fibre fracture is accompanied by a debonded area of a certain fixed length $L_{\mathrm{D}}$ at each fibre end (see Figure l). From Figure 1, it can easily be found that the stress recovery length or exclusion zone $\delta(\sigma)$ is determined by:

$$
\sigma=\frac{4}{d} L_{\mathrm{D}} \tau_{\mathrm{f}}+\frac{4}{d} \int_{L_{\mathrm{D}}}^{\partial} \tau \mathrm{d} x
$$

where $d$ represents the fibre diameter, $L_{\mathrm{D}}$ is the debonded length, $\tau_{\mathrm{f}}$ is the frictional shear stress and $\tau$ is the shear stress at the interface. Solving for $\delta(\sigma)$ yields:

$$
\delta(\sigma)=\frac{d \sigma}{4 \tau}-L_{\mathrm{D}}\left(\frac{\tau_{\mathrm{f}}}{\tau}-1\right)
$$

Using this new stress recovery length the following equations can be derived to describe the fragmentation process:

$$
\begin{gathered}
\frac{\mathrm{d} N}{\mathrm{~d} \sigma}=-\frac{L}{\frac{d}{4 \tau}\left(\sigma-\sigma_{\mathrm{D}}\left(1-\frac{\tau}{\tau_{\mathrm{f}}}\right)\right)^{2}} q(\delta ; \eta)+f\left(\sigma, L^{*}\right) \\
\frac{\mathrm{d} L}{\mathrm{~d} \sigma}=-\frac{L}{\left(\sigma-\sigma_{\mathrm{D}}\left(1-\frac{\tau}{\tau_{\mathrm{f}}}\right)\right)^{-}} q(\delta ; \eta) \\
\frac{\mathrm{d} P r}{\mathrm{~d} \sigma}=\frac{L}{\frac{d}{4 \tau}\left(\sigma-\sigma_{\mathrm{D}}\left(1-\frac{\tau}{\tau_{\mathrm{f}}}\right)\right)^{2}} q(\delta ; \eta)
\end{gathered}
$$

where $q(\delta, \eta)$ is a known distribution function similar to $P(x ; n, \delta)^{14.15}$ and $\sigma_{\mathrm{D}}=(4 / d) \tau_{\mathrm{f}} L_{\mathrm{D}}$. The initial conditions of the differential equations are $L(\sigma=0)=L_{\mathrm{T}}$, $N(\sigma=0)=0$ and $P_{\mathrm{R}}(\sigma=0)=0$. The MATLAB code ${ }^{19}$ was used to numerically solve these differential equations. For a more detailed discussion of the simulation principles and the various distributions for the fragment lengths, we refer the reader to the papers by $\mathrm{Curtin}^{14}$ and Widom $^{15}$

\section{NUMERICAL SIMULATION RESULTS}

The simulation program requires the input of seven parameters, these being the total fragmented fibre length $L_{\mathrm{T}}$, the debonded length $L_{\mathrm{D}}$, the fibre diameter $d$, the Weibull shape and scale parameters, $\rho$ and $\sigma_{0}$, respectively, the interfacial shear stress $\tau$, and the frictional shear stress $\tau_{\mathrm{f}}$. A survey of the tested specimen resulted in an average $L_{\mathrm{T}}$ of $20 \mathrm{~mm}$. The influence of each of the other parameters on the fragmentation process will be discussed in the following text.

In Figure $2 a$, the calculated final fragment length distribution $P$ is given for various values of the interfacial shear stress $\tau$. It can be seen that a high shear stress results in both a shift of the fragment length distribution to smaller fragment lengths and a narrowing of the fragment length distribution. Obviously, an increase in shear stress $\tau$ results in a faster stress build-up in the fibre and hence more fibre breaks, leading to shorter fragments with a more uniform length. This is also shown in Figure 3, in which the failure evolution as a function of the applied axial fibre stress $\sigma$ is plotted for various values of $\tau$. The influence of the Weibull shape 
Investigation into fibre fragmentation test: $P$. W. J. van den Heuvel et al.
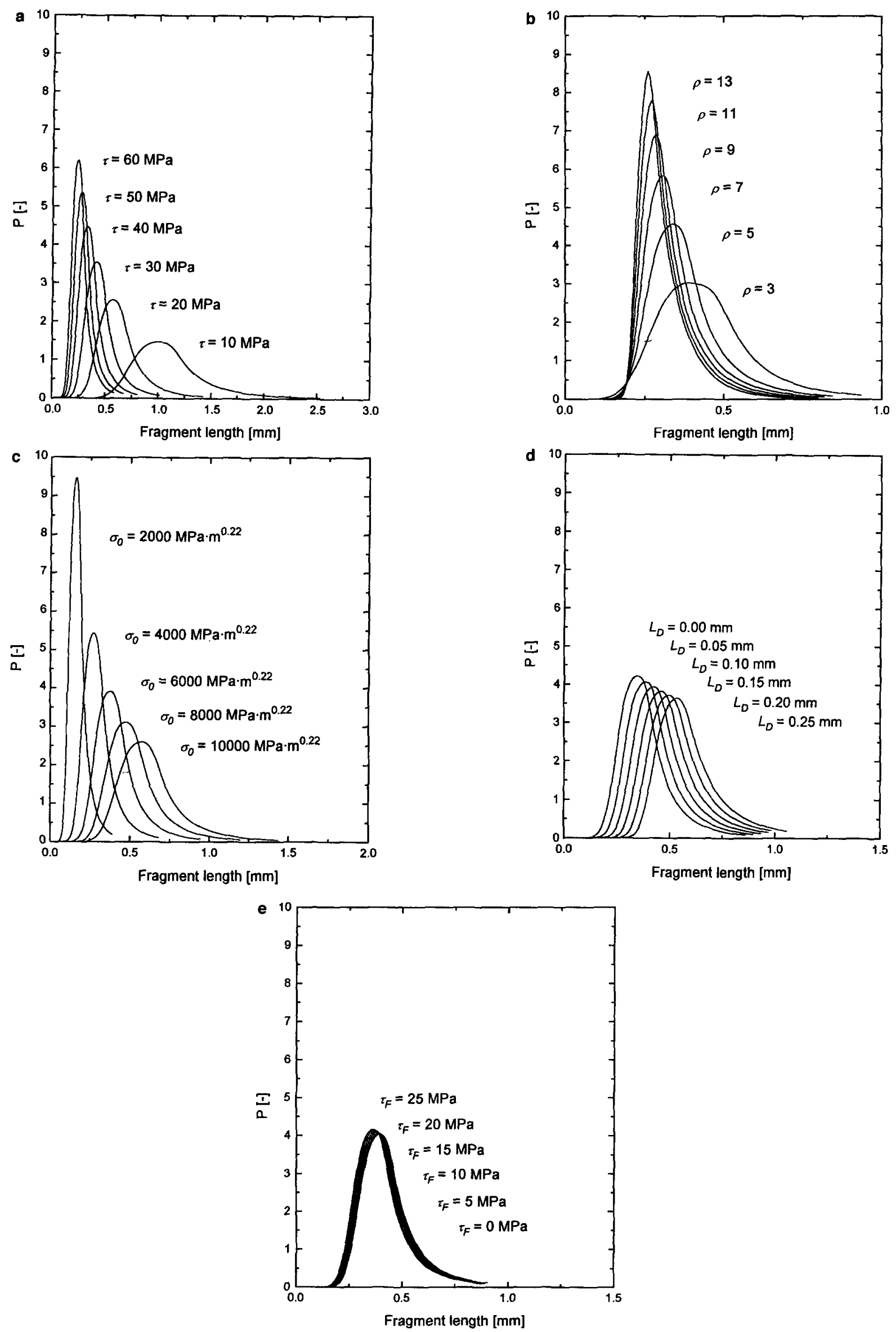

Figure 2 Predicted dependence of final fragment length distribution (P) on: (a) interfacial shear stress $\tau$; (b) Weibull shape parameter $\rho$; (c) Weibull scale parameter $\sigma_{0}$; (d) debonded length $L_{\mathrm{D}}$; and (e) frictional shear stress $\tau_{\mathrm{f}}$. The parameters held constant have the following values: $\rho=4.5$, $\sigma_{0}=5500 \mathrm{MPa} \mathrm{m}^{0.2}, \tau=37 \mathrm{MPa}, \tau_{\mathrm{f}}=10 \mathrm{MPa}, L_{\mathrm{D}}=0.008 \mathrm{~mm}$ 


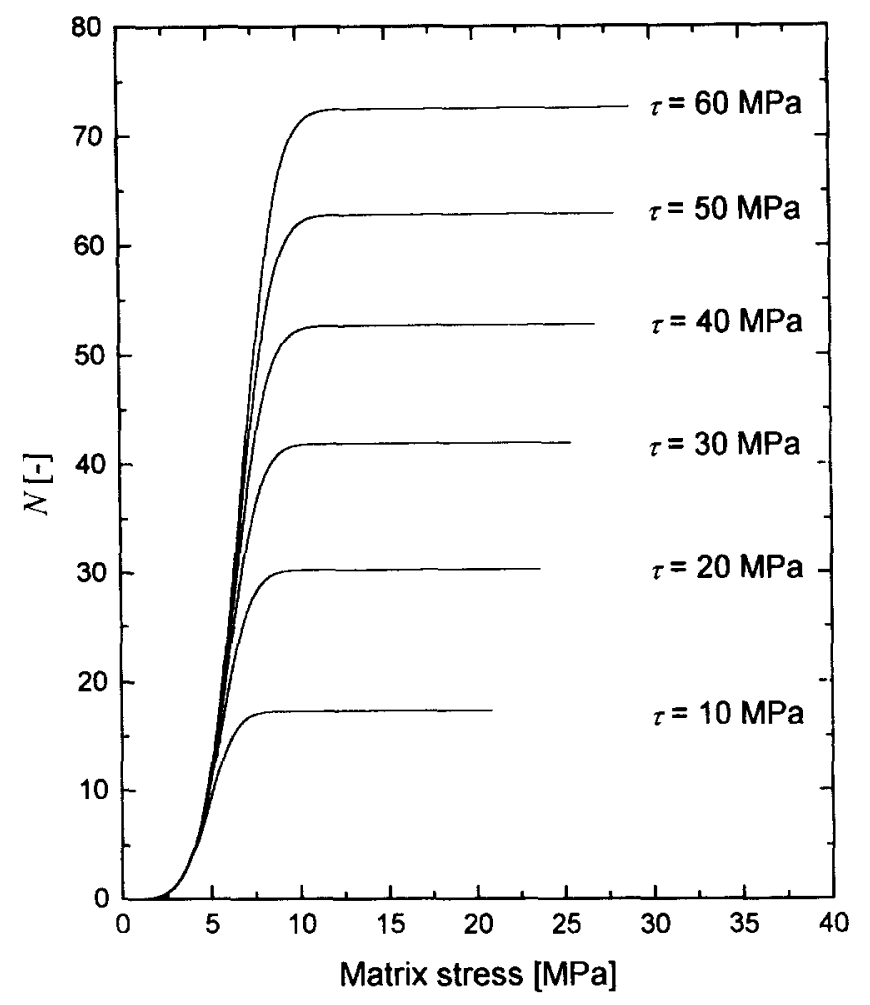

Figure 3 Influence of interfacial shear stress $(\tau)$ on evolution of number of fibre breaks during fibre fragmentation test. $\rho=4.5$, $\sigma_{0}=5500 \mathrm{MPa} \mathrm{m}^{0.22}, \tau=37 \mathrm{MPa}, \tau_{\mathrm{f}}=10 \mathrm{MPa}, L_{\mathrm{D}}=0.008 \mathrm{~mm}$

parameter $\rho$ on the fragment length distribution $P$ is given in Figure $2 b$. An increase in $\rho$ results in a decrease of the large fragment length section only, narrowing the distribution function without shifting the short length section towards smaller lengths. Regarding the Weibull scale parameter $\sigma_{0}$, a decrease in the amount of fibre breaks with increasing $\sigma_{0}$ is expected, since $\sigma_{0}$ represents the strength of a chain element of length $L_{0}$. Figure $2 c$ indeed shows that an increase in $\sigma_{0}$ results in a shift towards larger fragment lengths, i.e. less fragments, accompanied by a broadening of the peak. Figures $2 d$ and $e$ show that the influence of the debond length $L_{\mathrm{D}}$ and the frictional shear stress $\tau_{\mathrm{f}}$ on the final fragment length distribution $P$ is much smaller than the influence of the other parameters. As expected, it is observed that an increase in $L_{\mathrm{D}}$ results in longer fragments, whereas an increase in $\tau_{f}$ results in smaller fragments.

\section{EXPERIMENTAL DETAILS}

\section{Materials}

In the experimental part of this study, a polyacrylonitrile (PAN)-based intermediate modulus carbon fibre (Courtaulds, Apollo IM 43-750) was used. The fibres were unsized and, according to the manufacturer, had oxidative fibre surface treatment levels of $0,10,50,100$ and $200 \%$, where $100 \%$ is the commercial surface treatment level. The average fibre diameter was determined with a scanning electron microscope (Cambridge Stereoscan 200) and was $4.9 \pm 0.3 \mu \mathrm{m}$. The difference in fibre diameter between the various surface-treated fibres was within the experimental error. The dependence of the fibre strength on its length was determined by performing single-filament tensile tests according to ASTM D-3379. The gauge length was varied from 5 to $200 \mathrm{~mm}$. Figure 4 shows the strength-length dependence of the various carbon fibres. After correcting for the compliance of the system the single-filament tensile tests also provided the Young's modulus of the fibres $(285 \mathrm{GPa})$.

The matrix consisted of a common diglycidyl ether of bisphenol A (DGEBA)-type epoxy (Ciba Geigy, LY 556) and a stoichiometric amount of poly(oxypropylene)triamine curing agent (Texaco Jeffamine, T-403). The cure cycle for the epoxy was $24 \mathrm{~h}$ at room temperature followed by a post-cure at $75^{\circ} \mathrm{C}$ for $16 \mathrm{~h}$. This relatively low curing temperature was selected to minimize residual thermal stresses. The matrix had a Young's modulus of $3.5 \mathrm{GPa}$ and a strain to break of $\sim 4.5 \%$. The shear yield stress of the matrix was determined using a simple shear test set-up and measured $37 \mathrm{MPa}$ at a shear rate of $10^{-3} \mathrm{~s}^{-1}$

\section{Procedure}

Single-fibre composite (SFC) specimens were manufactured by placing a randomly chosen continuous filament in the cavity of a dog-bone shape silicone mould. To minimize the influence of differences in fibre pre-tension on the fibre fragmentation process ${ }^{20}$, each fibre was provided with a weight of $150 \mathrm{mg}$. After fixation of the filament to the mould with fast setting epoxy-based cement, pre-heated and degassed resin $\left(60^{\circ} \mathrm{C}, 400\right.$ torr $)$ was carefully injected into the mould. After placing a glass plate and a $3 \mathrm{~kg}$ weight on top of the mould, the resin was allowed to cure.

Fibre fragmentation tests were performed on a universal tensile machine (Frank 81565) equipped with an acoustic emission (AE) set-up (Physical Acoustics Corporation, Locan AT). For each fibre surface treatment level, five to eight samples were tested. By choosing

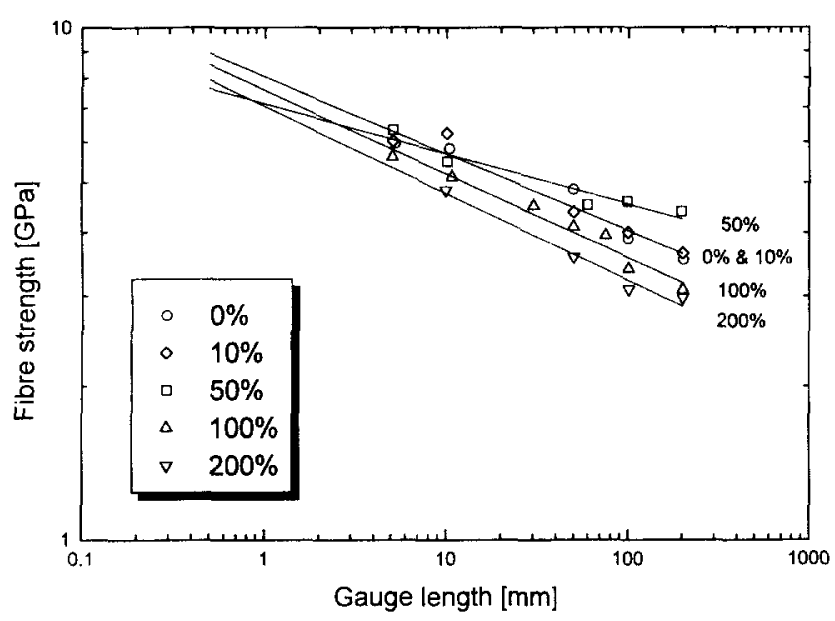

Figure 4 Influence of fibre length on its strength in air for Apollo IM 43-750 carbon fibres at various surface treatment levels 
appropriate $\mathrm{AE}$ settings and using a low strain rate $\left(10^{-4} \mathrm{~s}^{-1}\right)$, on-line monitoring of the fragmentation process was possible and, more importantly, complete fibre fragmentation, i.e. saturation, could be determined, at which point the fibre fragmentation test was stopped. After unloading, the saturated SFC specimens were investigated using a transmitted polarized light microscope equipped with a video camera and monitor. The fragment length $L$ and the debonded length were measured.

\section{EXPERIMENTAL RESULTS}

\section{Birefringence observations}

Figure 5 shows a series of polarized light micrographs showing the birefringence pattern around a fibre break at increasing strain for a $50 \%$ surface-treated carbon fibre. The observations in Figure 5 are representative for all surface-treated fibres, i.e. 10, 50, 100 and $200 \%$ surface treatment. As well documented, at the occurrence of a fibre rupture a bright sheath of birefringence arises at each side of the break, indicating highly stressed matrix $\operatorname{areas}^{1,12,21}$. Upon further straining, this sheath continuously grows towards the middle of the fibre. An

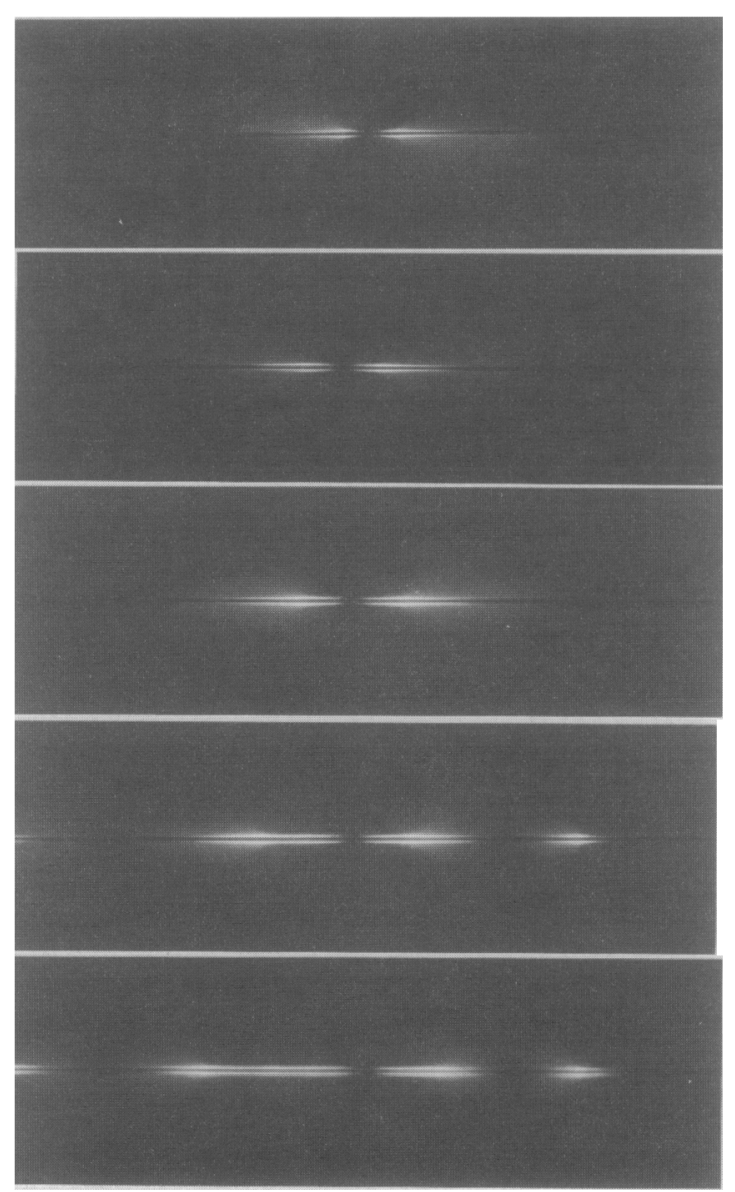

Figure 5 Transmitted polarized light micrographs of $50 \%$ surfacetreated Apollo IM 43-750 carbon fibre in an epoxy tensile bar at increasing strain, showing continuous growing of the birefringent shaft towards the middle of the fibre important observation made is that no fibre rupture occurs within these sheaths, strengthening Curtin's exclusion zone principle ${ }^{14}$. The similarity of the failure process for all of the surface-treated carbon fibres and the dissimilar failure process of the untreated carbon fibre are clearly shown in Figure 6. Whereas all the treated fibres show high birefringence activity, the untreated fibre hardly shows any birefringence due to extensive debonding. Apparently, in the case of an untreated fibre the stress transfer is very poor. Interestingly, a dramatic increase in fibre-matrix adhesion is already observed at a surface treatment level of $10 \%$. This is thought to be due to the removal of the weak defect-laden skin of the carbon fibre by the initial fibre surface treatment ${ }^{22}$.

In Figure 7, polarized light micrographs are presented of a tested specimen after unloading. For all fibre surface treatments, highly birefringent areas are still present. According to Bascom and Jensen these birefringent areas represent matrix areas in which plastic deformation, i.e. yielding, has taken place ${ }^{21}$. Some birefringence can also

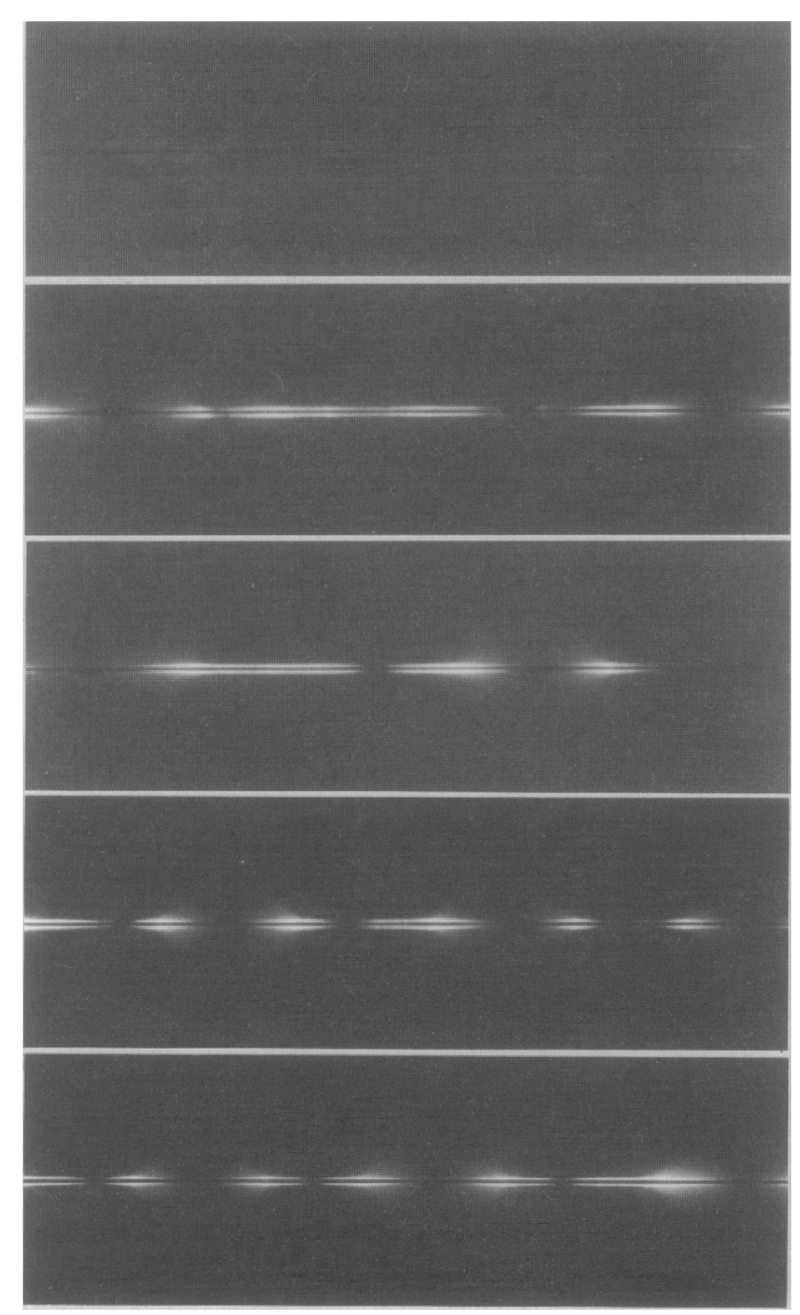

Figure 6 Transmitted polarized light micrographs of SFC specimen at saturation stage, showing the influence of fibre surface treatment on birefringence pattern, from top to bottom: untreated $(0 \%)$; $10 \%$ treated; $50 \%$ treated; $100 \%$ treated; and $200 \%$ treated Apollo IM 43-750 carbon fibre 

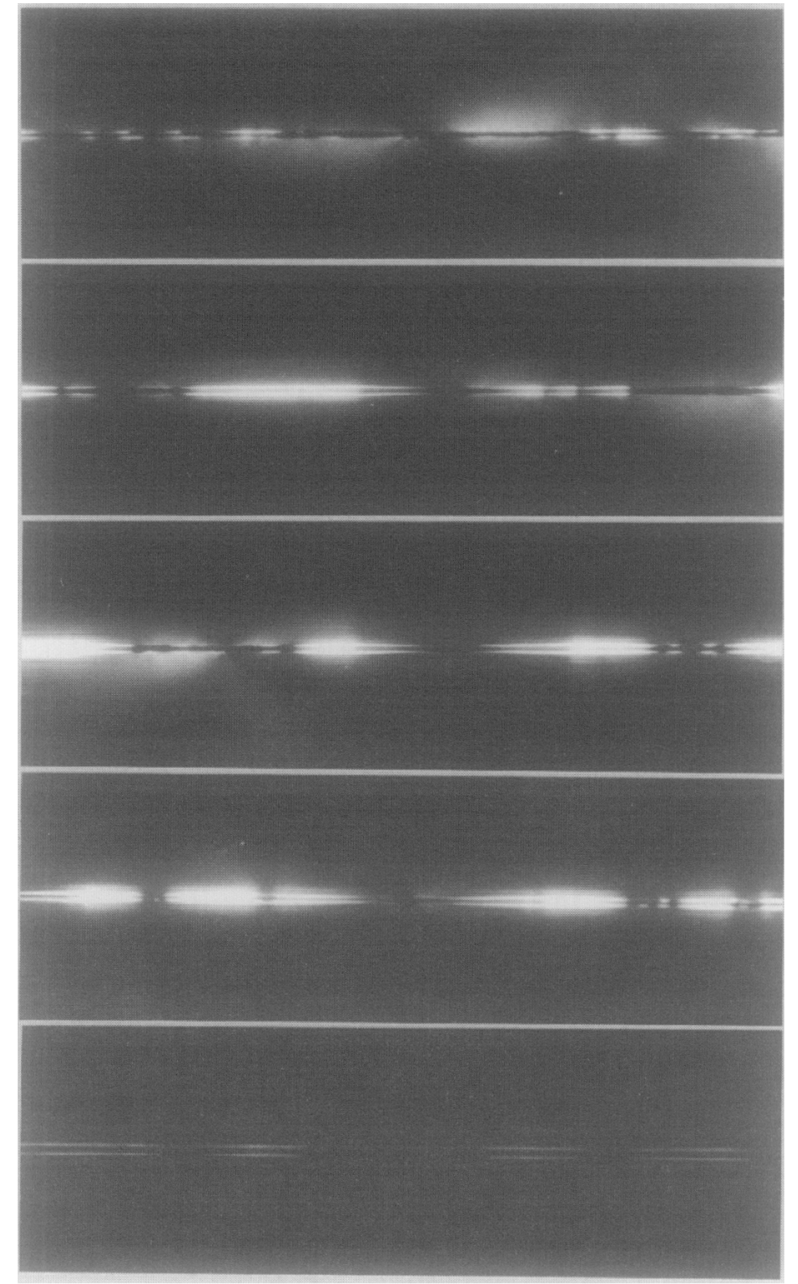

Figure 7 Transmitted polarized light micrographs of SFC specimen after unloading, showing plastic deformation in the matrix, from top to bottom: untreated $(0 \%) ; 10 \%$ treated; $50 \%$ treated; $100 \%$ treated; and $200 \%$ treated Apollo IM 43-750 carbon fibre

be observed in the debonded areas, due to residual friction between the fibre and the matrix ${ }^{12}$. Nevertheless, a good distinction between debonded and yielded areas can be made. Again, a large difference between the untreated and the $10 \%$ treated fibre is observed. Whereas the untreated fibre shows hardly any matrix yielding, the $10 \%$ fibre already shows a substantial amount. Furthermore, significant stick-slip behaviour ${ }^{12.21,23}$ is found for the untreated $(0 \%)$ fibre, apparent from the alternating dark and light areas in the stress recovery region. The $10 \%$ surface-treated fibre also shows some stick-slip behaviour, but to a much lower extent. Bascom and Jensen suggest that this stick-slip behaviour is caused by a heterogeneous surface, where the locus of failure is at the fibre surface or in the subsurface in some regions and shear yielding of the matrix in other regions ${ }^{21}$. This view is supported by Drzal et al., who stated that an initial oxidative fibre surface treatment removes the weak defect-laden outer skin of the carbon fibre ${ }^{22}$. An important consequence is that for the untreated $(0 \%)$ fibres the interface strength or the shear strength of the fibre skin is less than or equal to the shear yield stress of the matrix $(37 \mathrm{MPa})$ in some of the interface sections.
The same holds for the $10 \%$ surface-treated fibres, but for a significantly smaller part of the interface compared to the untreated fibres, since the amount of stick-slip behaviour is far less. At surface treatment levels higher than $10 \%$, no significant stick-slip behaviour was observed. Consequently, at surface treatment levels higher than $10 \%$ the interface strength becomes at least equal to the yield stress of the matrix at the interface. Importantly, this implies that now local yielding of the matrix near the interface becomes the limiting factor in the stress transfer, instead of the shear strength of the fibre-matrix interface or the fibre skin.

\section{Acoustic emission}

Before a quantitative evaluation of the fragmentation data can be made, the issue of saturation of the fibre fragmentation process has to be addressed. In Figure 8 , an $\mathrm{AE}$ plot representative for surface-treated fibres is presented, showing the evolution of the fibre fragmentation process in terms of the accumulated level of 'hits', i.e. fibre breaks. By selecting a threshold value of $35 \mathrm{~dB}$, we managed to keep the background noise at a very low level - an occasional one or two hits - without losing any fibre rupture signal. In all cases, the failure process starts at a strain of $\sim 1.5 \%$ and proceeds up to a strain of $2.5-3 \%$, i.e. the saturation stage is reached before macroscopic yielding of the matrix occurs. Furthermore, it is found that in the case of the treated fibres, the AE hits are in good agreement with the visually observed number of fragments, i.e. every failure is registered within an error of one or two breaks out of $40-50$ in total (depending on the level of fibre surface treatment). In the case of the untreated fibres, however, the number of hits is found to be considerably larger than that counted visually. Figure 9 shows that, whereas only one amplitude cloud can be observed in the case of treated fibres, in the untreated case an extra cloud is present at a lower noise level. It is believed that the lower-amplitude hits are caused by debonding and

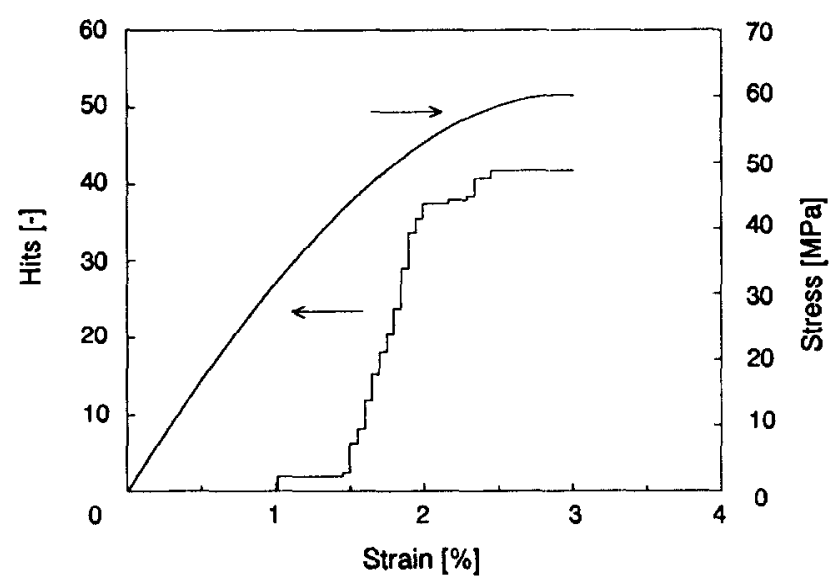

Figure 8 On-line recording of evolution of number of hits and stress strain curve during fibre fragmentation test of $100 \%$ surface-treated Apollo IM 43-750 carbon fibre 

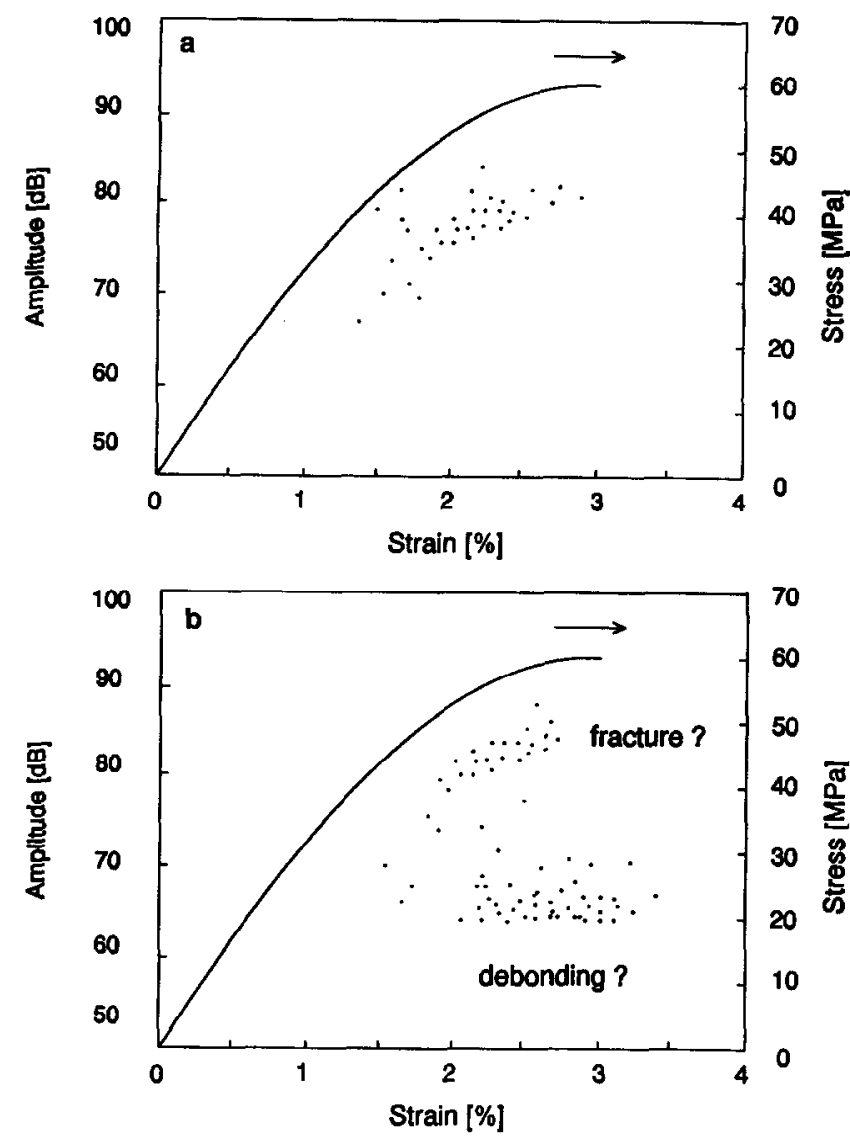

Figure 9 On-line rccordings of AE amplitude signal and stress-strain curve during fibre fragmentation test of: (a) $100 \%$ surface-treated; and (b) untreated (0\%) Apollo IM 43-750 carbon fibre

that the higher-amplitude hits are caused by fibre ruptures. To check this, the lower-amplitude hits were filtered from the overall signal. Now, for the untreated fibres also the remaining level of (higher-amplitude) hits is in good agreement with the visual count of the number of breaks.

\section{Length measurements}

In Figure 10, the final fragment length distributions are presented. It is clearly shown that, in going from a $0 \%$ treatment level to a $200 \%$ treatment level, the long fragments present in the untreated case disappear, leading to a narrow distribution positioned around a fragment length of $\sim 0.5 \mathrm{~mm}$. As in the visual observations, the largest change takes place when going from a $0 \%$ to a $10 \%$ surface treatment level. This can be seen even better in Figure 11, in which the mean fragment length $(\langle L\rangle)$ is plotted versus the surface-oxygen concentration, i.e. a measure for the ability of the carbon fibre surface to produce chemical bonds with the epoxy matrix. The surface-oxygen concentration data for the $0-100 \%$ surface-treated fibres are taken from Desaeger ${ }^{24}$, whereas the surface-oxygen concentration of the $200 \%$ surface-treated Apollo IM $43-750$ carbon fibre was measured on a Kraton XSAM 800

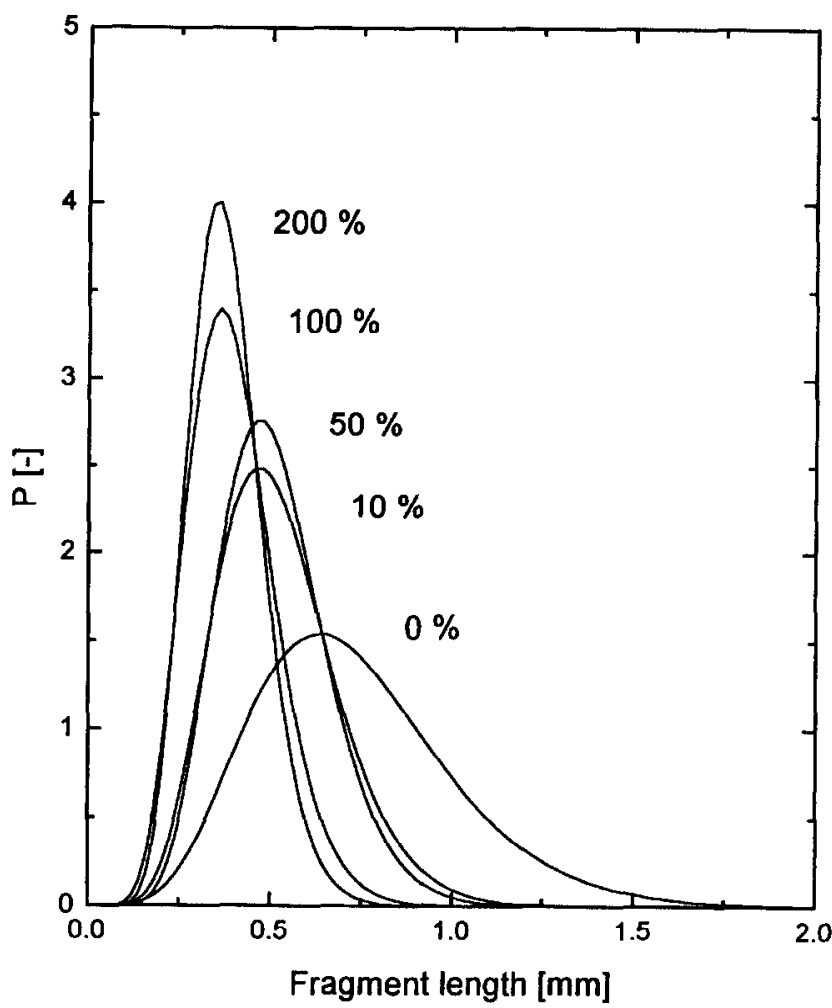

Figure 10 Influence of fibre surface treatment on final fragment distribution for Apollo IM 43-750 carbon fibre in epoxy matrix

X-ray photon spectrometer. All surface-oxygen concentrations are given in Table 1. Figure 11 also shows that a surface treatment level higher than $10 \%$, i.e. a surfaceoxygen concentration higher than $6.0 \%$, results in only a

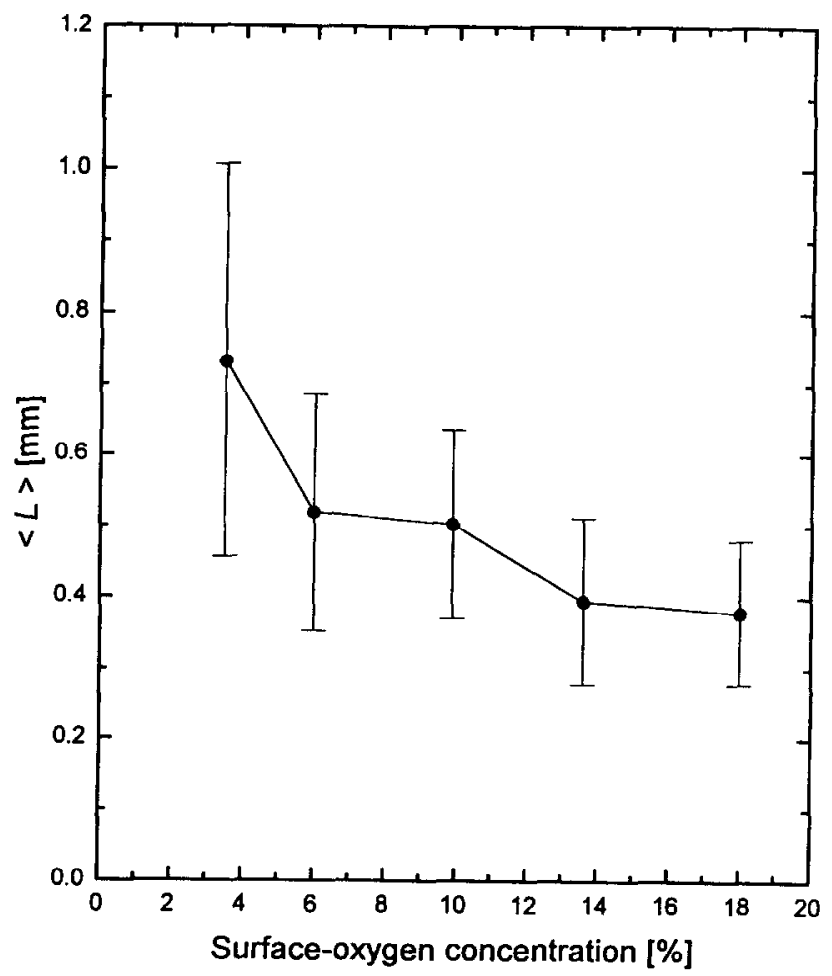

Figure 11 Influence of fibre surface treatment, in terms of surfaceoxygen content, on mean final fragment length $(<L>)$ 
Investigation into fibre fragmentation test: $P$. W. J. van den Heuvel et al.

Table 1 Fibre properties, length measurements and interfacial shear stresses for various fibres used (standard deviation given in brackets)

\begin{tabular}{|c|c|c|c|c|c|c|c|c|c|c|}
\hline Fibre & $\begin{array}{l}{\left[\mathrm{O}_{2}\right]^{*}} \\
(\%)\end{array}$ & $\begin{array}{l}\rho \\
(-)\end{array}$ & $\begin{array}{l}\sigma_{0} \\
\left(\mathrm{MPa} \mathrm{m}^{1 / \rho}\right)\end{array}$ & $\begin{array}{l}\langle L> \\
(\mathrm{mm})\end{array}$ & $\begin{array}{l}L_{\mathrm{C}} \\
(\mathrm{mm})\end{array}$ & $\begin{array}{l}L_{\mathrm{D}} \\
(\mathrm{mm})\end{array}$ & $\begin{array}{l}\sigma_{0}\left(L_{\mathrm{C}}\right) \\
\left(\mathrm{MPa} \mathrm{m}^{1 / \rho}\right)\end{array}$ & $\begin{array}{l}\tau_{\mathrm{Cox}}^{\dagger} \\
(\mathbf{M P a})\end{array}$ & $\begin{array}{l}\tau_{\text {Kelly }} \\
(\mathbf{M P a})\end{array}$ & $\begin{array}{l}\tau_{\text {Piggott }}^{\dagger} \ddagger \\
(\mathrm{MPa})\end{array}$ \\
\hline $0 \%$ & 3.5 & 6.7 & 8600 & $0.73(0.28)$ & 1.46 & 0.29 & 7600 & 235 & 13 & 162 \\
\hline $10 \%$ & 6.0 & 6.5 & 8800 & $0.52(0.17)$ & 1.04 & 0.05 & 8200 & 253 & 19 & 240 \\
\hline $50 \%$ & 9.9 & 10.3 & 7500 & $0.50(0.13)$ & 1.01 & 0.04 & 7100 & 220 & 17 & 210 \\
\hline $100 \%$ & 13.6 & 6.1 & 8100 & $0.39(0.12)$ & 0.79 & 0.02 & 7900 & 243 & 24 & 238 \\
\hline $200 \%$ & 18.0 & 5.9 & 7600 & $0.38(0.10)$ & 0.76 & 0.004 & 7400 & 228 & 24 & 227 \\
\hline
\end{tabular}

* Surface-oxygen data for 0-100\% taken from ref. 24; surface-oxygen concentration of 200\% Apollo IM 43-750 was measured on a Kraton XSAM $800 \mathrm{X}$-ray photon spectrometer

${ }^{\dagger}$ Influenced matrix area assumed to be 10 fibre radii

${ }^{\ddagger}$ Frictional shear stress $=10 \mathrm{MPa}$

slight decrease of the mean fragment length towards a constant level, as also found by Baillie and Bader ${ }^{25}$. The dependence of the total debonded length of each fragment $\left(2 L_{\mathrm{D}}\right)$ on the surface-oxygen concentration is presented in Figure 12 (see also Table 1). It is shown that a $10 \%$ surface treatment substantially decreases the total debonded length per fragment from $\sim 80 \%$ of the mean fragment length to $\sim 20 \%$ of the mean fragment length. Apparently, there is a large improvement in the fibre-matrix interface strength resulting in a change of failure mode. It is now believed that by applying a $10 \%$ surface treatment the predominant failure mode changes from either interface failure or failure of the fibre skin, to matrix failure in the form of shear yielding, as shown in Figure 7. In the shear yielding failure mode it is observed that a further increase in surface-oxygen concentration, i.e. surface treatment level, results in a continuous decrease of the debonded length. At a $200 \%$ surface treatment level, the total debonded length relative to the mean fragment length is $\sim 4 \%$. This continuous decrease in debonded length indicates a continuous increase in fibre-matrix adhesion, i.e. interface strength. Hence, following Wagner et al. ${ }^{26}$, who have proposed a fracture mechanics-based (i.e. energy-based) interpretation of interfacial adhesion, it is believed that the debonded length may be a useful parameter to determine the interfacial strength.

Desaeger et al. reported on measurements of the increasing length of the bright shaft of birefringence during the fibre fragmentation test ${ }^{27}$. The same carbon fibres were used, i.e. Courtaulds Grafil Apollo IM 43750 , with surface treatments of $0,10,50$ and $100 \%$. In their experiments Desaeger et al. refer to the length of the birefringent zone as the debonded length, but according to our belief this length must represent the total of the debonded zone and the yielded $z^{27}{ }^{27}$. A rate of 'decohesion' inversely proportional to the surfaceoxygen concentration was reported. However, by correcting the rate of 'decohesion' for the mean fragment length the same rate of 'decohesion' is found for all surface-trcated fibres. Now, rather than supporting the idea of debonding, this indicates that the dominant failure mode is local yielding of the matrix, because local yielding of the matrix is not influenced by the degree of fibre-matrix adhesion. Hence, the results reported by
Desaeger et al. ${ }^{27}$ support our view of a locally yielding matrix in cases of good fibre-matrix adhesion.

\section{Classical stress transfer models}

Before comparing the experimental results to the predictions of the numerical simulation, we will first discuss the results of some of the classical stress transfer theories. The shear-lag model developed by $\operatorname{Cox}^{2}$ and the model presented by Kelly and Tyson ${ }^{3}$ were used to calculate the shear strength of the fibre-matrix interface. These models all require a value for the critical length $L_{C}$. Currently, a commonly accepted way to derive the critical length from raw fragmentation data is not available $^{28}$. A method frequently used to derive the critical length from the fragment length distribution is to multiply the mean fragment length (i.e. the expected value of a fitted Gaussian distribution) by $4 / 3$, since it is assumed that the lengths are uniformly distributed between $L_{\mathrm{C}} / 2$ and $L_{\mathrm{C}}$, with a mean length of $(3 / 4) L_{\mathrm{C}}{ }^{29}$.

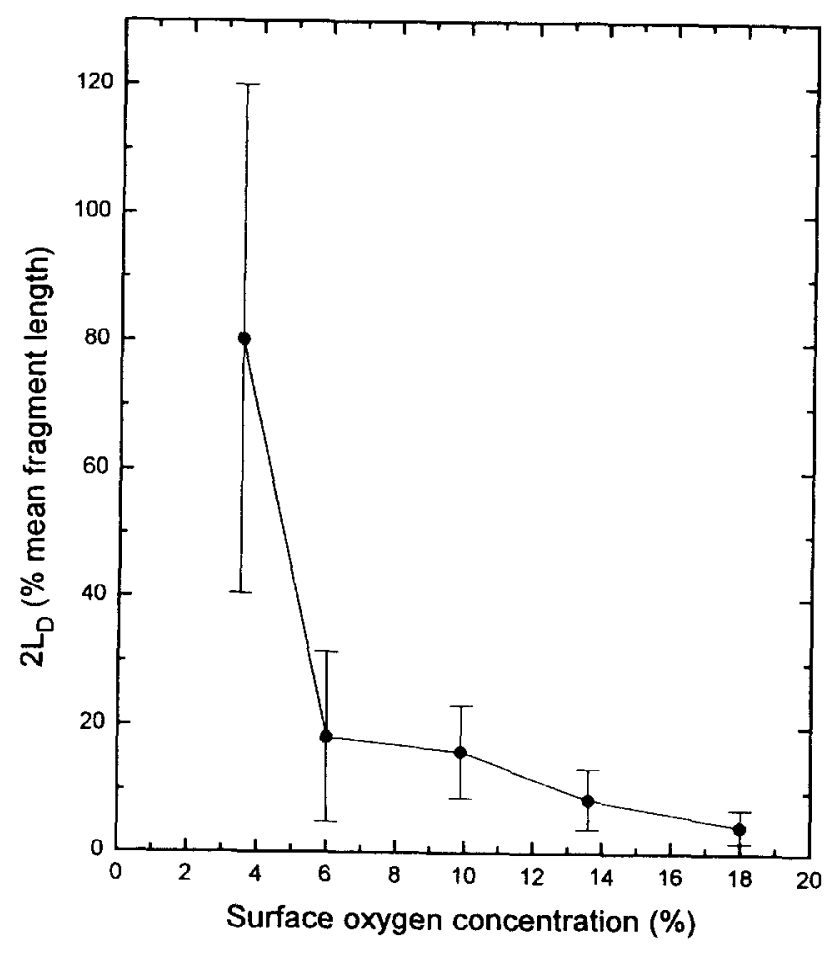

Figure 12 Influence of fibre surface treatment. in terms of surfaceoxygen content, on debonded length $L_{D}$ 
This method is, however, heavily criticized by many researchers since the length distributions are far from uniform, as shown in Figure $10^{11,12,28}$. Therefore, in order to obtain a value for $L_{C}$, we arbitrarily defined another route involving the gamma distribution. From our experience, the gamma distribution is found to fit the final fragment length distributions of all fibre surface treatment levels better than the usually used Gaussian distribution. Now, the expected value of the fitted gamma distribution is assumed to correspond with half the critical length, since a fragment with a length equal to the critical length is expected to break in half. The resulting critical lengths are listed in Table 1 . We do realize that this method is a rather simplistic one, but it is satisfactory in the present context. It should, however, be noticed that the resulting critical lengths are approximately equal to the largest fragment lengths found in the experiments.

The interfacial shear stresses calculated according to Cox $^{2}$ and Kelly and Tyson ${ }^{3}$ are listed in Table 1. In these calculations, the fibre strengths at the critical length are taken from Figure 4 . With respect to the influenced matrix area $r_{\mathrm{m}}$ needed in the Cox model, values for $r_{\mathrm{m}}$ varying from 5 to 300 times the fibre radius are reported in the literature ${ }^{12,13,28,30}$. In our calculations $r_{\mathrm{m}}$ was given a value of 10 times the fibre radius. In Table 1 , it is shown that both the elastic shear-lag models, i.e. Cox's model ${ }^{2}$ and Piggott's model $^{5}$, yield interfacial shear stresses much higher than the shear yield stress of the matrix (37 MPa). As also noted by Melanitis et al., this is thought to be rather unrealistic ${ }^{13}$. On the other hand, the KellyTyson model $^{3}$ yields much more realistic interfacial shear stress values. However, the calculated shear stresses are all well below the shear yield stress of the matrix (37 MPa). Especially in the case of untreated fibres, a very low shear stress is calculated (13 MPa). This can be explained by the fact that in the case of untreated fibres, fibre-matrix debonding takes place instead of matrix yielding. Thus, the stresses in the fibres are predominantly built up through the transfer of frictional shear stresses. The calculated value of $13 \mathrm{MPa}$ is in close agreement with values for the frictional shear stress reported in the literature ${ }^{11}$. Regarding the surfacetreated fibres, an important reason why the calculated shear stresses are lower than the experimental shear stress is the fact that the method of calculation used is a relatively simple one, which does not take into account the statistical and dynamic aspects of the ongoing fragmentation process. In other words, one cannot expect to correctly describe a statistically based process, with continuously changing yielding zones and fragment lengths, which such a simplistic model. Howcver, in the following it will be shown that a numerical simulation of the fibre fragmentation process using the concept of a yielding matrix can describe the fibre fragmentation process better.

\section{EXPERIMENT VERSUS SIMULATION}

Figure 13 shows the experimental and predicted final fragment length distributions for the 50,100 and the $200 \%$ surface-treated carbon fibres. For the predicted distributions the experimentally determined matrix yield stress of $37 \mathrm{MPa}$ was used. The other parameters used in the calculations are listed in Table 1. Good agreement between experimental and predicted fragment length distributions is found for the $200 \%$ surface-treated fibre. The $100 \%$ surface-treated fibre shows a fair agreement, whereas poor agreement is found for the $50 \%$ surfacetreated fibre. A reason for the poor agreement found for the $50 \%$ surface-treated fibre could be the way the debonded length was included in the model. In our simulation of the fragmentation test a fixed debonded length was assumed, whereas in reality the debonded length is distributed. The more distributed the debonded length, the less agreement between experiment and prediction. Hence, a relatively large disagreement between experiment and prediction is expected in the case of the $50 \%$ surface-treated fibre. This distribution in debonded length also explains the predicted fragment lengths being larger than those found experimentally in the cases of the 100 and $200 \%$ treated fibres. For a debonded length shorter than the average debonded length, as assumed in the simulation, makes shorter fragment lengths possible.

The good agreement between experiment and prediction found in the cases of good adhesion, i.e. in the cases of the 100 and $200 \%$ surface-treated fibres, implies that in the fragmentation test the stress is predominantly transferred to the fibre through a yielding matrix, confirming our view of the mechanics of the fibre fragmentation test. As already mentioned, it is believed that at low strains, i.e. before any fibre fracture has occurred, the stress profile in the fibre can be described solely by Cox's shear-lag model, as reported by Huang and Young? . However, in our case a debonded region is formed at the occurrence of fibre fracture due to the sudden release of elastic strain, and behind the debonded region the stress transfer is limited by the shear yield stress of the matrix. This representation of the mechanics of the fibre fragmentation test has an important implication: the classical theories for stress transfer in the fibre fragmentation test are unsuitable for calculating the fibre-matrix interface strength. However, an indication of the fibre-matrix interface shear strength can be obtained for three distinct cases: 1) the occurrence of yielding implies that the shear strength of the fibrematrix interface is higher than the shear yield stress of the matrix; 2) stick-slip indicates that the shear strength of the fibre-matrix interface or the outer skin of the fibre approximately equals the shear yield stress of the matrix; and 3) significant debonding indicates that the shear strength of the fibre-matrix interface or outer skin of the fibre is lower than the shear yield stress of the matrix. 

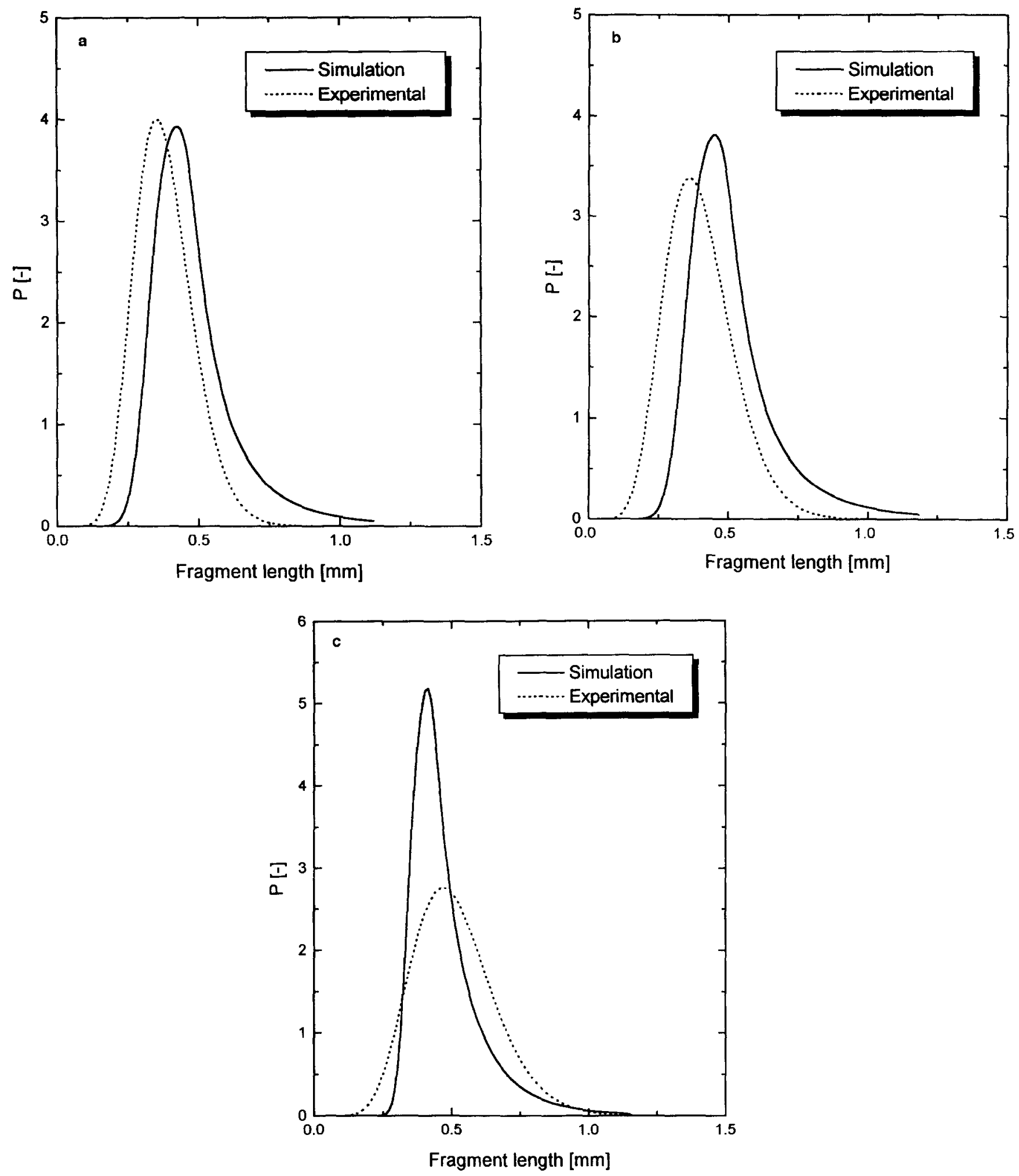

Figure 13 Comparison of experimental and predicted final fragment length distributions for: (a) $200 \%$ surface-treated; (b) $100 \%$ surface-treated; and (c) $50 \%$ surface-treated Apollo IM 43-750 carbon fibre in epoxy matrix

\section{CONCLUSIONS}

Numerical simulations based on an exact solution of the fibre fragmentation test were performed using the concept of fibre-matrix debonding and local matrix yielding at the fibre-matrix interface. The influences of the matrix shear yield stress, the Weibull parameters of the fibre, the frictional shear stress and the debonded length on the final fragment length distribution were investigated. It was found that both the debonded length and the frictional shear stress only have a minor influence on the fragment length distribution.

Single-fibre fragmentation tests on carbon/epoxy microcomposites with different levels of fibre-matrix 
adhesion were performed using carbon fibres with fibre surface treatment levels varying from 0 to $200 \%$ of the commercial fibre surface treatment. Polarized light optical microscopy showed that applying a $10 \%$ surface treatment results in a change in failure mode: whereas substantial fibre--matrix debonding and stick-slip behaviour is observed in the case of untreated fibres, an intermediate surface treatment of $10 \%$ results in considerable matrix yielding at the fibre-matrix interface and a substantial decrease in the debonded length.

A comparison between predicted final fragment length distributions using the shear yield stress of the matrix and measured final fragment length distributions was made for surface treatment levels of 50,100 and $200 \%$. Good agreement was found for the 100 and $200 \%$ surface-treated fibres, indicating that the stress is transferred to the fibre through a locally yielding matrix. For the $50 \%$ surface-treated fibre the predictions were far less good, probably due to the large variation in the debonded length.

Importantly, because of the occurrence of local matrix yielding near the fibre-matrix interface the classical theories of stress transfer in the fibre fragmentation test do not determine the fibre-matrix interface strength. However, an indication of the fibre-matrix interface shear strength with respect to the shear yield stress of the matrix can be obtained for three distinct cases: 1) the occurrence of yielding indicates that the shear strength of the fibre-matrix interface is higher than the shear yield stress of the matrix; 2) the occurrence of stick-slip behaviour indicates that the shear strength of the fibrematrix interface or the outer skin of the fibre approximately equals the shear yield stress of the matrix; and 3) the occurrence of significant debonding indicates that the shear strength of the fibre-matrix interface or outer skin of the fibre is lower than the shear yield stress of the matrix.

Regarding a quantitative determination of the fibrematrix interface strength with the fibre fragmentation test we believe that, based on the presented results, a fracture mechanics (i.e. energy) approach is a promising method. Then, the fibre-matrix interface strength can be related to the amount of fibre-matrix debonding resulting from a fibre fracture.

\section{ACKNOWLEDGEMENTS}

The authors would like to thank the Huntsman Corporation Belgium NV for supplying the Jeffamine T-403 curing agent and Courtaulds P.l.c. for supplying the carbon fibres. Patrick Eumelen is gratefully acknowledged for his help with the fibre fragmentation tests.

\section{REFERENCES}

1 Herrera-Franco, P.J. and Drzal, L.T., Comparison of methods for the measurement of fibre/matrix adhesion in composites. Composites, 1992, 23, 2-27.

2 Cox, H.L., The elasticity and strength of paper and other fibrous materials. British Journal of Applied Physics, 1952, 3, 72-79.
3 Kelly, A. and Tyson, W.R., Tensile properties of fibrereinforced metals: copper/tungsten and copper/molybdenum. Journal of the Mechanics and Physics of Solids, 1965, 13, 329350.

4 Lhotellier, F.C. and Brinson, H.F., Matrix-fibre stress transfer in composite materials: elasto-plastic model with an interphase layer. Composite Structures, 1988, 10, 281-301.

5 Piggott, M.R., Expressions governing stress-strain curves in short fibre reinforced polymers. Journal of Materials Science, $1978,13,1709-1716$

6 Melanitis, N. and Galiotis, C., Interfacial micromechanics in model composites using laser Raman spectroscopy. Proceedings of the Royal Society of London - Series A, 1993, 440, 379-398.

7 Huang, Y. and Young, K.J. Analysis of the fragmentation test for carbon-fibre/epoxy model composites by means of Raman spectroscopy. Composites Science and Technology, 1994, 52, 505-517.

8 Pitkethly, M.J., Favre, J.P., Gaur, U., Jakubowski, J., Mudrich, S.F., Caldwell, D.L., Drzal, L.T., Nardin, M., Wagner, H.D., DiLandro, L., Hampe, A., Armistead, J.P., Desaeger, M. and Verpoest, I. A round-robin programme on interfacial test methods. Composites Science and Technology, 1993, 48, 205214.

9 Favre, J.P., Sigety, P. and Jacques, D., Stress transfer by shear in carbon fibre model composites. Part 2: Computer simulation of the fragmentation test. Journal of Materials Science, 1991, 26, $189-195$.

10 Ling, S. and Wagner, H.D., Relationship between fiber flaw spectra and the fragmentation process: a computer simulation investigation. Composites Science and Technology, 1993, 48, 35- 46 .

11 Henstenburg, R.B. and Phoenix, S.L., Interfacial shear strength studies using the single-composite filament test. Part II: A probability model and Monte Carlo simulation. Polymer Composites, $1989,10,389-408$

12 Netravali, A.N., Henstenburg, R.B., Phoenix, S.L. and Schwartz, P., Interfacial shear strength studies using the single-filament composite test. Part I: Experiments on graphite fibers in epoxy. Polymer Composites, 1989, 10, 226-241.

13 Melanitis, N., Galiotis, C., Tetlow, P.L. and Davies, C.K.L. Interfacial shear stress distribution in model composites: the effect of fibre modulus. Composites, 1993, 24, 459-466.

14 Curtin, W. Exact theory of fibre fragmentation in a singlefilament composite. Journal of Materials Science, 1991, 26, 5239-5253.

15 Widom, B., Random sequential addition of hard spheres to a volume. The Journal of Chemical Physics, 1969, 44, 3888-3894.

16 Feillard, P., Désarmot, G. and Favre, J.P., A critical assessment of the fragmentation test for glass/epoxy systems. Composites Science and Technology, 1993, 49, 109-119.

17 Mullin, J., Berry, J.M. and Gatti, A., Some fundamental fracture mechanisms applicable to advanced filament reinforced composites. Journal of Composite Materials, 1968, 2, 82-103.

18 Bader, M.G., Tensile strength of uniaxial composites. Science and Engineering of Composite Materials, 1988, 1, 1-11.

19 MATLAB User's Manual, Version 4.0a. The Math Works Inc. Natick, MA, 1993.

20 Scherf, J. and Wagner, H.D., Interpretation of fibre fragmentation in carbon/epoxy single fibre composites: Possible fibre pre-tension effects. Polymer Engineering and Science, 1992, 32, 298-304.

21 Bascom, W.D. and Jensen, R.M., Stress transfer in single fibre resin tests. Journal of Adhesion, 1986, 19, 219-239.

22 Drzal, L.T., Madhukar, M. and Waterbury, M.C., Adhesion to carbon fiber surfaces: Surface chemical and energetic effects. Composite Structures, 1994, 27, 65-71.

23 Drzal, L.T., Rich, M.J. and Lloyd, P.F., Adhesion of graphite fibres to epoxy matrices: I. The role of fibre surface-treatment. Journal of Adhesion, 1983, 16, 1-30.

24 Desaeger, M., An integrated theoretical and experimental study of the fibre-matrix interface in carbon-epoxy composites. Ph.D. thesis. Katholieke Universiteit Leuven, Belgium, 1993.

25 Baillie, C.A. and Bader, M.G., Investigation of the strength of surface treated carbon fibres embedded in resin, by means of model composite tests. Composites Science and Technology, 1993, 48, 103-108.

26 Wagner, H.D., Nairn, J.A. and Detassis, M., Toughness of interfaces from initial fiber-matrix debonding in a single fiber 
composite fragmentation test. Applied Composite Materials $1995,2,107-117$

27 Desaeger, M., Verpoest, 1. and Robinson, R., Study of the parameters which control the interface strength properties in carbon epoxy systems. In Proceedings of Interfacial Phenomena in Composite Materials (IPCM-91), eds I. Verpoest and F.R. Jones, Butterworth-Heinemann, Oxford, 1991, pp. 87-92.

28 Feillard, P., Désarmot, G. and Favre, J.P., Theoretical aspects of the fragmentation test. Composites Science and Technology, $1994,50,265-279$

29 Ohsawa, T., Nakayama, T., Miwa, A. and Hasegawa, A., Temperature dependence of the critical fibre length for the glass fibre-reinforced thermosetting resins. Journal of Applied Polymer Science, 1978, 22, 3203-3212.

30 Guild, F.J., Vlattas, C. and Galiotis, C., Modelling of stress transfer in fibre composites. Composites Science and Technology, 1994, 50, 319-332.

\section{NOMENCLATURE}

$\delta(\sigma) \quad$ stress recovery length $(\mathrm{m})$

$\sigma \quad$ undisturbed stress $(\mathbf{P a})$

$P(x ; n, \delta) \quad$ distribution of fragments larger than $\delta(\sigma)(-)$

$P_{\mathrm{R}}(x)$ $x$

$n$

$\rho$

$\sigma_{0}$

$<L>$

$L_{\mathrm{C}}$

$L_{\mathrm{D}}$

$d$

$\tau_{\mathrm{f}}$

$T$

$N$

$L_{\mathrm{R}}$

$L^{*}$

$\delta_{\mathrm{D}}$

$L_{0}$

$q(\delta ; \eta)$

$L_{\mathrm{T}}$

$r_{\mathrm{m}}$

$P$ fragment length (m)

break density ( )

Wiebull shape parameter $(-)$

Wcibull scale parameter $\left(\mathrm{MPa} \mathrm{m}^{1 / \rho}\right)$

mean fragment length $(\mathrm{m})$

critical length $(\mathrm{m})$

debonded length $(\mathrm{m})$

fibre diameter $(\mathrm{m})$

frictional shear stress $(\mathrm{Pa})$

shcar stress at interface $(\mathrm{Pa})$

number of breaks (-)

rcmaining length $(\mathrm{m})$

remaining length able to incorporate another fibre break (m)

Dirac delta function (-)

fibre length associated with $\sigma_{0}(\mathrm{~m})$

distribution function; see refs 14 and 15

total fibre length $(\mathrm{m})$

influenced matrix area $(\mathrm{m})$

final fragment length distribution ( ) 